\title{
Study on phytoremediation for heavy metal contaminated sediments by hydrophytes
}

\author{
Tao Ma ${ }^{1}$, Wenhui Zhang ${ }^{1}$, Hongkai $\mathrm{Fan}^{1}$, Lizhu Huang ${ }^{1}$, Qing $\mathrm{Xu}^{2}$, Guangxiang $\mathrm{Ma}^{1, *}$, Guofeng Zhou ${ }^{1}$, Yingjie Meng ${ }^{1}$, \\ Jianzhang $\mathrm{Sun}^{1}$, Jinwei Qiu ${ }^{1}$, Junjie $\mathrm{Gu}^{1}$, Xingsheng Kang ${ }^{1}$
}

${ }^{1}$ Shandong Huankeyuan Environmental Engineering Co., Ltd, Jinan 250101, China

${ }^{2}$ Yishui Branch of Linyi Municipal Ecology and Environment Bureau, Yishui 276400, China

\begin{abstract}
The remediation performances of heavy metals contaminaged sediment by hydrophytes including Alternanthera Philoxeroides, Canna indica L., Nymphaea tetragona, Typha orientalis, Phragmites australis, Phragmites australis, Hydrilla verticillata, Cyperus alternifolius L., Eichhornia crassipes, Acorus tatarinowii, Digitaria sanguinalis (L.) Scop were investigated through batch pot experiments. The results showed that the enrichment effect of $\mathrm{Pb}$ was better in Alternanthera Philoxeroides and Acorus tatarinowii with the BCFs of 4.42 and 1.22, and the TFs of 7.84 and 4.23 , respectively. The Cr enrichment effects by Nymphaea tetragona, Hydrilla verticillata and Eichhornia crassipes (Mart.) Solms were better, which BCFs were $2.69,1.91$ and 3.71, and which TFs were 7.93, 2.07 and 2.18, respectively.
\end{abstract}

\section{Introduction}

With the rapid development of industry and agriculture, heavy metal pollution in soils or sediments in rivers is becoming increasingly serious [1]. Soil/sediment contaminated by heavy metals will not only have a direct impact on plant growth and development [2], but also accumulate in vegetables, food crops and fruits, seriously affecting the yield and safety of agricultural products and further endangering human health through the food chains [3]. On the other hand, heavy metals in soil can also enter rivers [4], lakes and groundwater through rainwater and runoff, thus seriously endangering the safety of the ecosystem [5]. Heavy metal pollution in urban reaches is mainly distributed in economically developed cities in the southeastern China [6]. The data shows that the contamination rate of sediment in China reaches $80.1 \%$ [7].

The remediation techniques for contaminated sediments can be divided into in-situ and ex-situ remediation technologies [8]. Ex-situ remediation technology could remove the contaminants completely [10], but the costs are high and there is a risk of contaminants spreading. The in-situ remediation technology, especially the phytoremediation technology, was got more attentions recently, with its advantages of low cost [11], and without secondary pollution. Phytoremediation is a kind of bioremediation technology [13], removing pollutants from sediments by absorption, volatilization, transformation and degradation of plants and their rhizosphere microbial system [14]. It is widely concerned for its advantages of purifying water body [15], removing nitrogen and phosphorus pollutants from sediments in rivers or lakes [16], and having landscape view.
The aim of this study is to investigate the remediation performance of the common hydrophytes used in artificial wet land in heavy metal contaminated sediments through batch pot experiments.

\section{Materials and methods}

\section{1 experimental materials}

\subsubsection{Sediment sample}

The sediment was taken from the middle reaches of Xiaoqing river in Jinan, Shandong Province, China. The physicochemical characteristics of the sediment samples are shown in Table 1.

Table 1. Physicochemical characteristics of sediment

\begin{tabular}{|c|c|c|c|c|c|c|}
\hline $\begin{array}{c}\text { index } \\
\text { samples }\end{array}$ & $\mathrm{pH}$ & $\begin{array}{c}\text { Organic } \\
\text { matter }\end{array}$ & $\mathrm{TN}$ & $\mathrm{TP}$ & $\mathrm{Pb}$ & $\mathrm{Cr}$ \\
\hline $\begin{array}{c}\text { soil } \\
\text { sample }\end{array}$ & 7.41 & 84.34 & $\begin{array}{c}4.6 \\
7\end{array}$ & 8.12 & $\begin{array}{c}214.9 \\
8\end{array}$ & $\begin{array}{c}417 . \\
45\end{array}$ \\
\hline
\end{tabular}

\subsubsection{Hydrophytes}

The 10 hydrophytes in this experiment are common species in lakes, rivers and wetlands, including Alternanthera Philoxeroides, Canna indica L., Nymphaea tetragona, Typha orientalis, Phragmites australis, Phragmites australis, Hydrilla verticillata, Cyperus alternifolius L., Eichhornia crassipes, Acorus tatarinowii, Digitaria sanguinalis (L.) Scop. All the plants were got from the nursery garden for artificial wetland in suburb of Jinan city (China).

\footnotetext{
*Corresponding author: mxiang0812@sina.com
} 


\subsection{Experimental design}

The young seedlings of hydrophytes were planted in 20 L plastic buckets, each plant set two parallel samples. The sediment samples were used as the cultivated soil for the hydrophytes. Add $10 \mathrm{Kg}$ of well-mixed sediment and fully aerated tap water to the soil, all of these happened 30 days before buying the seedling. The whole experiment was set up blank control, and the operation of the blank group was the same as the experimental group [18]. The seedlings of 10 plants were respectively planted in the above prepared bucket, and 6-8 plants were evenly implanted in each bucket, while the blank group was not implanted.

This experiment was carried out in May 2018. 1 plants of each species were collected for testing on the 7th, 14th, 34th, 66th, 91st and 120d, as well as the rhizosphere soil of the plant. The plants were rinsed with tap water, and then rinsed with distilled water. Each plant was divided into aboveground and underground parts. The processed samples were put into the oven for 30 minutes at $105{ }^{\circ} \mathrm{C}$, and roasted to constant weight at 75 ${ }^{\circ} \mathrm{C}$. The soil samples were directly baked in the oven at $75{ }^{\circ} \mathrm{C}$ until constant weight, and then taken out and grinded in a 100-mesh sieve for testing [19].

\subsection{Chemical analysis}

Sediment $\mathrm{pH}$ was determined using portable $\mathrm{pH}$ meter (Thermo Orien 240A) in a 1:2.5 soil-water suspension; The content of determination includes soil total nitrogen, Soil total phosphorus, Soil organic matter, $\mathrm{Pb}$ and $\mathrm{Cr}$. Heavy metal fraction extraction was determined by Tessier method. Tessier method divides heavy metals into five forms: exchangeable state, carbonate bound state, iron-manganese oxide bound state, organic bound state and residual state [20].

For heavy metal concentration determinations, the dried Sediment samples $(0.300 \mathrm{~g})$ or powdered plants samples $(0.100 \mathrm{~g})$ were digested with a $5 \mathrm{ml}$ mixture of $\mathrm{HNO}_{3}-\mathrm{HClO}_{4} \quad(5: 1 ; \mathrm{v} / \mathrm{v})$ and diluted to $25 \mathrm{ml}$ with ultrapure water in microwave oven (Mars 6, CEM, USA). All of the above solutions were stored at $4{ }^{\circ} \mathrm{C}$ prior to analysis. The concentrations of $\mathrm{Pb}, \mathrm{Cr}$ were measured by the atomic absorption spectrophotometer (TAS-990, Puxi company, Beijing). All the samples were analyzed in triplicate [21].

\subsection{Data analysis}

The SPSS software was used for data statistical analysis. Bioconcentration factor (BCF) is the ratio of heavy metal accumulated by plants to that dissolved in the aquatic medium. Here, two BCF were computed from the plant parts (root and frond) as

$$
\mathrm{BCF}=\mathrm{C}_{\text {frond }} / \mathrm{C}_{\mathrm{Sd}}
$$

Translocation factor (TF) of heavy metals were calculated as

$$
\mathrm{TF}=\mathrm{C}_{\text {frond }} / \mathrm{C}_{\text {root }}
$$

\section{Results and discussion}

\subsection{Accumulation of heavy metals by plants}

The BCF and TF changes of $\mathrm{Pb}$ and $\mathrm{Cr}$ for the 10 plants during the $120 \mathrm{~d}$ were shown in Fig. 1. and Fig. 2., respectively.
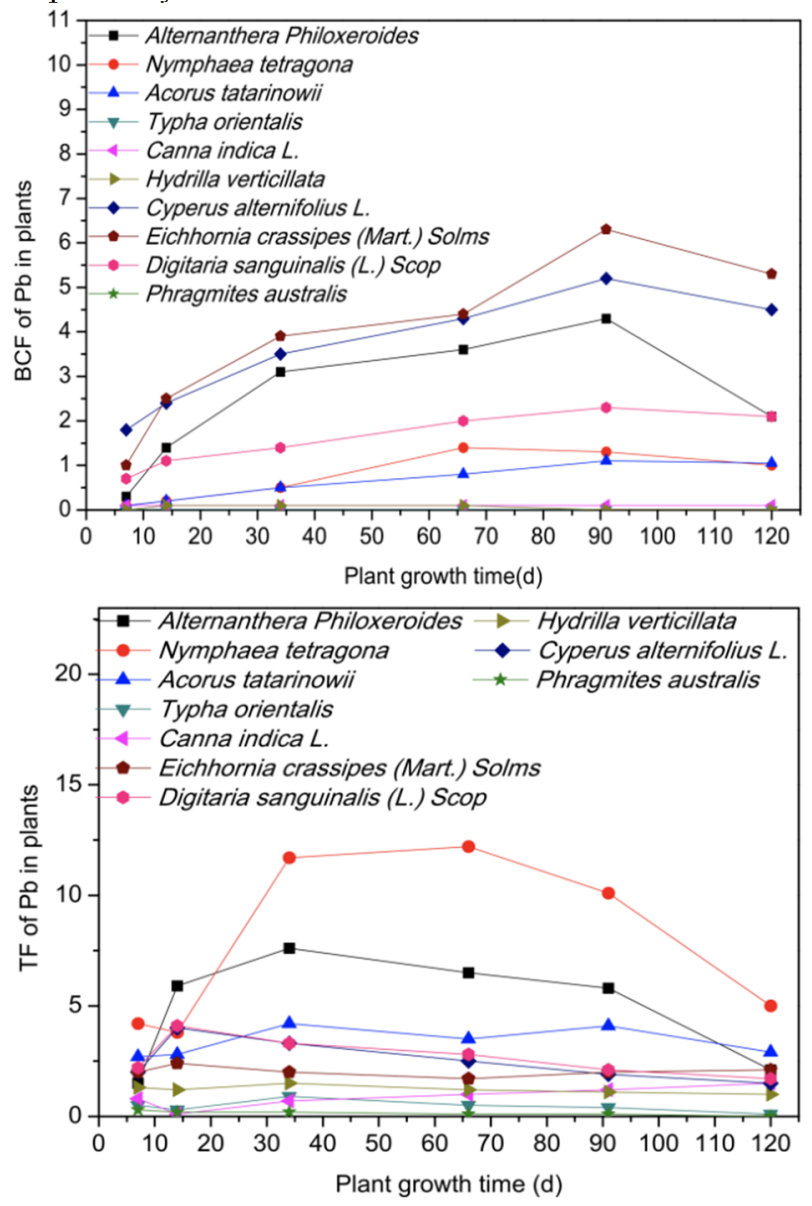

Fig. $1 \mathrm{BCF}$ and TF changes of $\mathrm{Pb}$ by hydrophytes over times

It can be seen from Fig. 1 that the $\mathrm{BCF}$ values for $\mathrm{Pb}$ of the six plants, including Alternanthera Philoxeroides, Nymphaea tetragona, Acorus tatarinowii, Cyperus alternifolius L., Eichhornia crassipes (Mart.) Solms and Digitaria sanguinalis (L.) Scop, showed a trend of first rising and then falling over 120 days. The BCF values of the other four plants is far less than 1. According to the change of TF of all plants, all other plants is greater than 1 except Typha orientalis and Phragmites australis, which indicates that the heavy metals absorbed were mainly concentrated in the aboveground parts of plants. Considered the $\mathrm{BCF}$ and $\mathrm{TF}$ values of $\mathrm{Pb}$ from these plants, $\mathrm{Pb}$ can be enriched by Alternanthera Philoxeroides, Nymphaea tetragona, Acorus tatarinowii, Cyperus alternifolius L., Eichhornia crassipes (Mart.) Solms and Digitaria sanguinalis (L.) Scop.

As can be seen from Fig. 2, The value of BCF of Nymphaea tetragona, Hydrilla verticillata and Eichhorniacrassipes (Mart.) Solms were bigger than 1, 

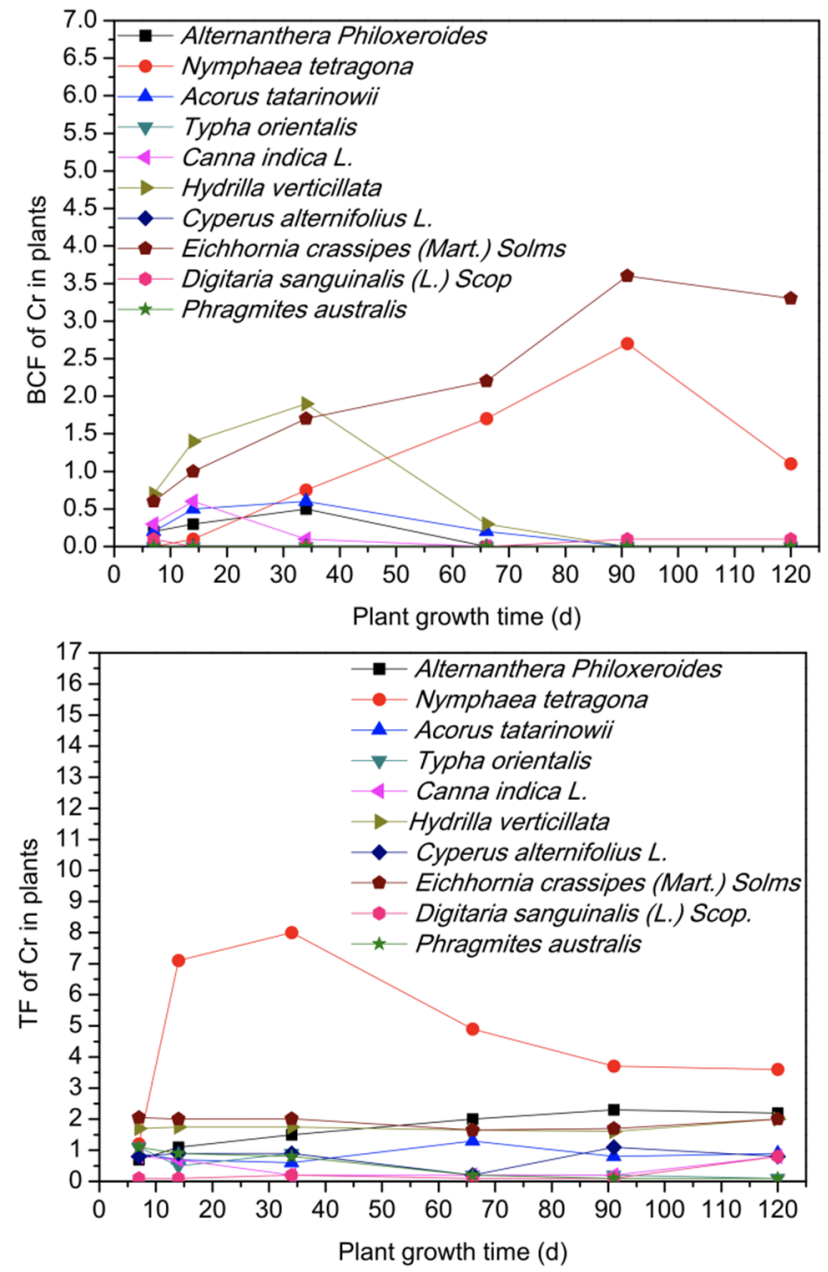

Fig. 2 BCF and TF changes of $\mathrm{Cr}$ by hydrophytes over times

and the $\mathrm{BCF}$ value showed a trend of first rising and then falling in the whole test process. From the change of TF of each plant, it can be seen that TF of four plants, such as Alternanthera Philoxeroides Nymphaea tetragona, Hydrilla verticillata and Eichhornia crassipes (Mart.) Solms is greater than 1 , while TF of the other six plants is all less than 1. Considering the BCF and TF values of $\mathrm{Cr}$ of each plant, Nymphaea tetragona, Hydrilla verticillata and Eichhornia crassipes (Mart.) Solms have a good accumulation effect on $\mathrm{Cr}$, which can be used in phytoremediation technology [22].

\subsection{Heavy metal speciations in sediment}

The existence form of heavy metal elements in sediment is an important parameter to measure its environmental effect. By analyzing the change of heavy metal speciations in sediment before and after plant growth, the bioavailability and toxicity of heavy metals can be determined, and the impact of plant planting on the environment can be evaluated [23]. The growth process of plants directly or indirectly influences the speciations of heavy metals in sediment by rhizosphere secretion and rhizosphere microorganisms. During the $120 \mathrm{~d}$ experiment, the morphology changes of heavy metal speciations in the growing soil of the 10 plants were shown in Fig. 3 and Fig. 4, respectively.

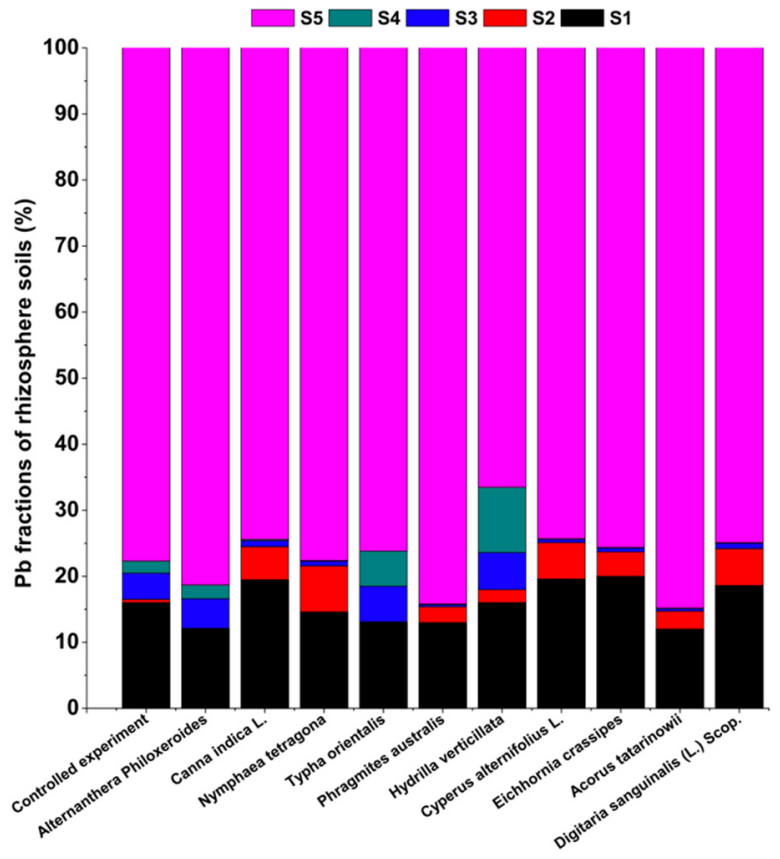

Fig. $3 \mathrm{~Pb}$ fractions in the soils with different plant in $120 \mathrm{~d}$ (S1- exchangeable fraction; S2- carbonate bond fraction; S3iron manganese oxide binding fraction; S4- organic binding fraction; S5 - residual fraction)

As shown in Fig. 3, the fractions of $\mathrm{Pb}$ in soils with different plants were different each other, also with the control group. Compared to the control group, the heavy metal fractions increased greatly in the soils with the plants, such as Canna indica L., Nymphaea tetragona, Cyperus alternifolius L., Eichhornia crassipes and Digitaria sanguinalis (L.) Scop. Based on the environmental safety, the rise of exchageable fracition of $\mathrm{Pb}$ significantly increase the biological activity and diffusion of $\mathrm{Pb}$. As for as the carbonate bond fraction of $\mathrm{Pb}$ in the soils is concerned, it decreased in the control group, while most of soil samples with plants increased, especially for Cyperus alternifolius L., with the increasement from $0.8 \%$ to $5.5 \%$. For the residual fraction, it decreased in the soils with the plants such as Canna indica L., Typha orientalis, Hydrilla verticillata, Cyperus alternifolius L., Eichhornia crassipes, Digitaria sanguinalis (L.) Scop, which have the chance to increase the sediment ecological risk of $\mathrm{Pb}$. 


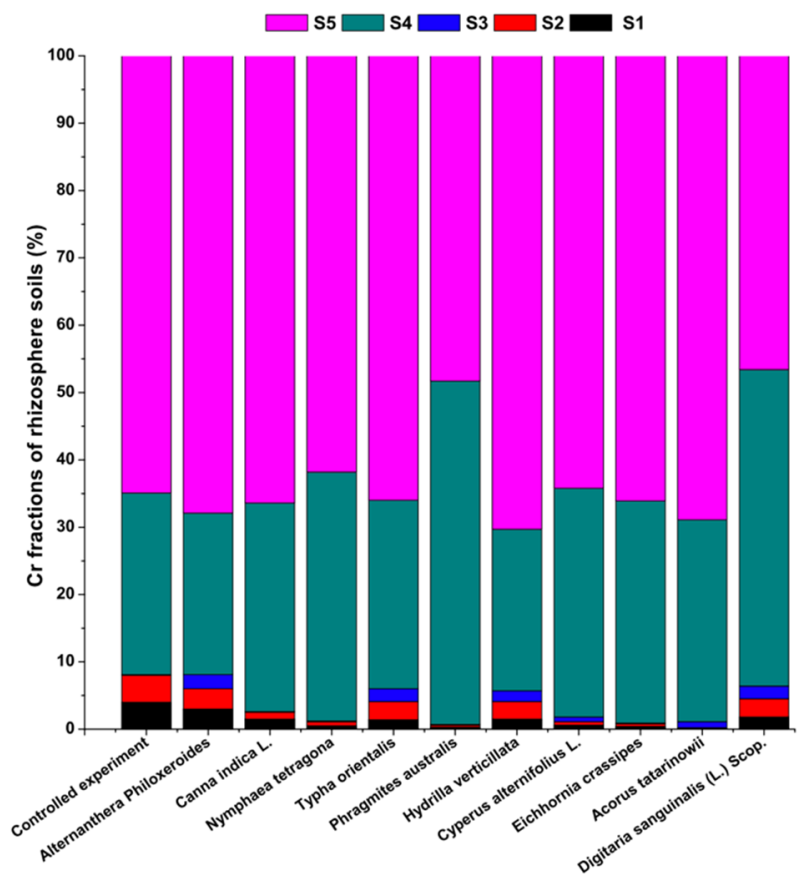

Fig. $4 \mathrm{Cr}$ fractions in the soils with different plant in $120 \mathrm{~d}$ (S1- exchangeable fraction; S2- carbonate bond fraction; S3iron manganese oxide binding fraction; S4- organic binding fraction; S5 - residual fraction)

As shown in Fig. 4, compared to the controlled experiment, the exchangeable and carbonate bond fractions in the soils with all of plants decreased after $120 \mathrm{~d}$, the iron manganese oxide binding fractions increased in all groups except Nymphaea tetragona. As for organic binding fraction, it increased significantly in soils with Canna indica L., Nymphaea tetragona, Cyperus alternifolius L., Eichhornia crassipes and Digitaria sanguinalis (L.) Scop. For residual fraction, it increased in soils with plants except Phragmites australis and Digitaria sanguinalis (L.) Scop. [25]. Therefore, it would not increase the ecological risk of $\mathrm{Cr}$ for sediment remediation with the most of hydrophytes mentioned above.

\section{Conclusion}

The remediation of $\mathrm{Pb}$, and $\mathrm{Cr}$ contaminated sediments by hydrophytes were carried out in batch pot experiments over $120 \mathrm{~d}$. The results showed that Alternanthera Philoxeroides and Acorus tatarinowii could have an effective accumulation for $\mathrm{Pb}$ in the contaminated sediments, while the plants, such as Nymphaea tetragona, Hydrilla verticillata and Myriophyllum verticillatumL could have an effective accumulation for $\mathrm{Cr}$ in the contaminated sediments.

\section{Acknowledgment}

We thank the Foundation of contaminated sediment remediation in Shandong Province (No. 2017-HCZBLY-003) and Shandong Key Scientific and Technical Innovation Project (No. 2018YFJH0902) for supporting this research.

\section{References}

1. A. Cristaldi, G. O. Conti, E. H. Jho, P. Zuccarello and M. Ferrante, Environmental Technology \& Innovation 8, 309-326 (2017).

2. M. S. Bhuyan and M. A. Bakar, Environ Sci Pollut Res Int 24 (35), 1-14 (2017).

3. A. E. Burakov, E. V. Galunin, I. V. Burakova, A. E. Kucherova and V. K. Gupta, Ecotoxicology \& Environmental Safety 148, 702-712 (2017).

4. L. Xiao, D. Guan, M. R. Peart, Y. Chen and J. Dai, Chemosphere 185, 868 (2017).

5. R. Mazurek, J. Kowalska, M. Gąsiorek, P. Zadrożny and K. Orłowska, Chemosphere 168, 839-850 (2017).

6. L. Wang, W. Tao, R. C. Smardon, X. U. Xue and L. U. Xinwei, Frontiers of Earth Science 12 (2) (2018).

7. T. Rasheed, M. Bilal, F. Nabeel, I. Hmn, C. Li and Y. Zhou, 615, 476-485 (2018).

8. G. Zhao-hui, T. Wei-jia, P. Chi, H. Bo, X. Xi-yuan and X. Qing-hua, Journal of Agro-Environment Science (2017).

9. L. A. Ndeda, S. Manohar and G. M. Macharia, (2017).

10. Y. Yang, L. Wei, L. Cui, M. Zhang and J. Wang, Clean - Soil Air Water 45 (3) (2017).

11. M. S. Wu, X. Xu, Q. Zhao and Z. Y. Wang, Rsc Advances 7 (84), 53433-53438 (2017).

12. J. Lee, K. Y. Park, J. Cho and J. Y. Kim, Chemosphere 191, 520-526 (2017).

13. M. J. M. Yusof, M. T. Latif and S. F. M. Yusoff, presented at the THE 2017 UKM FST POSTGRADUATE COLLOQUIUM: Proceedings of the University Kebangsaan Malaysia, Faculty of Science and Technology 2017 Postgraduate Colloquium, 2018 (unpublished).

14. J.-t. Fu, D.-m. Yu, X. Chen, Y. Su and Y.-p. Wei, Journal of Mountain Science (3), 1-17 (2019).

15. A. Ltifi, N. Saidi, M. Rabhi, J. Downer, A. Smaoui, C. Abdellly and A. Hafiane, (2017).

16. S. Ganguly, S. Khare and A. A. Waoo, Current Environmental Engineering 4 (1), - (2017).

17. R. Kamusoko and R. M. Jingura, CLEAN - Soil Air Water 45 (11), 1600437 (2017).

18. K. J. Panchal, R. B. Subramanian and T. P. Gohil, 2017 (unpublished).

19. J. Antonkiewicz, B. Kołodziej and E. J. Bielińska, International Journal of Phytoremediation 19 (4), 309-318 (2017).

20. S. Lal, S. Ratna, O. B. Said and R. Kumar, 10 (2018).

21. G. Saxena, D. Purchase, D. S. I. Mulla, G. D. Saratale and R. N. Bharagava, Reviews of environmental contamination and toxicology (2019).

22. H. S. Shehata, International journal of Environmental Science and Technology (1) (2018). 
23. M. J. Noufal, Z. A. Maalla, D. J. Noufal and A. A. Hossean, (2017).

24. Z. Yarahmadi, J. Baharlouei, R. Shokoohi, M. Y. Alikhani and N. Shirmohammadi-Khorram, Petroleum Science \& Technology 35 (7), 647-652 (2017).

25. V. Subhashini and A. V. V. S. Swamy, Potential of Catharanthus roseus (L.) in Phytoremediation of Heavy Metals. (2017). 